\title{
RELIABILITY BASED DESIGN OF THE ROCK SIDE SLOPE FOR MIDDLE PLATEAU IN MOKATTAM AREA CONSIDERING OPTIMAL COST VALUE
}

\author{
Yasser Abdul-Hai Hegazy, Sherif Adel Akl and Haitham Mohamed Adel \\ Department of Soil Mechanics \& Foundations, Faculty of Engineering, Civil Engineering, \\ Cairo University
}

\begin{abstract}
Design solutions for the problems of the rock side slope stability, in general, are one of the most critical issues in geo-technical engineering profession, due to the fact that the values of rock parameters are difficult to be considered reliable, because of the uncertainties existing in geological system. This research aims to introduce reliability based design of the rock side slope stability considering optimal cost value. The idea for obtaining the optimal cost value depends on two main critical parameters. These two main critical parameters are uni-axial compressive strength (U.C.S) and geologic strength index (G.S.I). Both of them have been calculated based on statistical calculations of mean and standard deviations. A strength criterion is needed to characterize the rockmass in geotechnical engineering. There are three criteria are used to describe the strength of a material: bilinear Mohr-Coulomb criterion, nonlinear Hoek-Brown criterion and special spalling criterion must be used in special case of massive, brittle rocks. Nonlinear Hoek-Brown criterion has been used in this study; because of some limitations associated with the use of the Mohr-Coulomb criterion. RocData program have been utilized for obtaining the Hoek-Brown parameters (m, s), Slide program has been employed for calculating the reliability index, factor of safety and probability of failure for middle plateau in Mokattam area. The concept of design is based on the necessity of using reinforcement. If the design of using rock parameters is safe and reliable, there is no need for reinforcement; otherwise design of rock bolts should be used as a support system to improve reliability and factor of safety. The current simplified method has been utilized to consider the cost of failure to find the optimal length of support and optimal reliability index. The study concluded that the suggested technique of nonlinear Hoek Brown Criterion is effective for helping the designer in finding the optimal length of support that meets the optimal reliability index and optimal cost value for 2 main critical parameters.
\end{abstract}

Key Word: Reliability- Rocks- Probability- Side Slope- Cost

\section{INTRODUCTION}

\subsection{Slopes}

Slope failures of different types are affected by some factors such as angle of internal friction, slope geometry, geological structure, etc... [1].As a result of these factors there are many types of slope failure such as plane failure, wedge failure, etc...There are many techniques used for analyzing of these types of slope failures, which are wedge failure analysis, circular failure analysis, etc... [2]. Design stages takes place after analysis in order to protect the side slope of rocks. Most rock slopes need some forms of treatment to ensure continued stability. Rock bolt/nail (this is tensioned bar inserted into rock forming a short anchorage zone in rock so that an unstable slope area is being reinforced by tension. Typical rock bolts are $25 \mathrm{~mm}$ to 
$40 \mathrm{~mm}$ in diameter, $3 \mathrm{~m}$ to $6 \mathrm{~m}$ long, and have a tensile working load around $100 \mathrm{kN}$ [3].In slope stabilization, each slope must be treated individually; local practices may be considered as a good guide for this purpose. The flatter the slope, the greater are the excavation costs but the less the long-term maintenance costs. The principal design decision is often whether to form the slope in a series of benched steps or to cut to a uniform gradient. This indicates the importance of rock bolts reinforcement for slope stabilization [4].

\subsection{Uncertainty}

Uncertainty in geological system stems from:

1. variability caused by random process (Aleatory), which is:

A. Natural variability in rock mass

B. Natural variability in In-situ stress parameters,

2. knowledge-based uncertainty that exists due to lack of information (Epistemic), which is:

A. Site characterization uncertainty: that refers to the accuracy of the geological model, which is affected by data and exploration uncertainties such as measurement errors, data handling/transcription errors, and inadequate data coverage.

B. Parameter uncertainty: that results from inaccuracy in assessing geotechnical parameters from tests data. The major components are statistical Estimation errors and transformation errors (i.e. transforming intact to rockmass parameters), both of which are exacerbated by a few observations.

C. Model uncertainty: that deals with the degree to which a mathematical model adequately mimics reality. This stems from either an inability to identify the best model or the inability of a model to represent a system's true physical behavior. Reliability-based design will be used as an approach to incorporate possible uncertainties values in the design. However, the results are affected by the assumed distribution and statistical parameters of the rock properties [5].

\subsection{Hoek Brown}

In general, most computer programs require Mohr-Coulomb soil parameters $\left(C^{\prime}\right.$ and $\left.\varphi^{\prime}\right)$ as input. Thus ignoring the non-linear nature of the rock mass failure envelope. Furthermore, the non-linearity is more pronounced at the low confining stresses that are operational in slope stability problems. As discussed by Merifield et al. [6], the Hoek-Brown failure criterion is one of the few non-linear criteria used by practicing engineers to estimate rock mass strength. The latest version of Hoek-Brown yield criterion is expressed as:

$\sigma 1^{`}=\sigma 3^{`}+\sigma \mathrm{ci}((\mathrm{mb} \sigma 3 ` \sigma \mathrm{ci})+(\mathrm{s}))^{\mathrm{a}}$.....

Where:

$\mathrm{mb}=\mathrm{mi} \exp ((\mathrm{GSI}-100) /(28-14 \mathrm{D}))$

$\mathrm{s}=\exp ((\mathrm{GSI}-100) /(9-3 \mathrm{D}))$

$\alpha=(1 / 2)+((1 / 6)(\mathrm{e}-\mathrm{GSI} / 15-\mathrm{e}-20 / 3)) \ldots \ldots \ldots \ldots . .(4)$

with the magnitudes of $\mathrm{mb}, \mathrm{s}$ and a relying on the geological strength index (GSI), which describes the rock mass quality, and oci and mi representing the intact uniaxial compressive strength and material constant respectively. The parameter $\mathrm{D}$ is a factor that depends on the degree of disturbance whose range is between 0 and 1. Currently, only the studies of Li et al. [7, 8 and 9] provided both the numerical upper and lower bound solutions [19-21] for rock slope assessments based on the Hoek-Brown failure criterion [10]. In Li et al. [7], a new nondimensional stability number $(\mathrm{N})$ was proposed. It is based on the Hoek-Brown failure criterion and defined as

$\mathrm{N}=\sigma \mathrm{ci} / \gamma \mathrm{HF}$

Where $\gamma$ is the unit weight of the rock mass, and $\mathrm{H}$ and $\mathrm{F}$ are the height and the safety factor of the slope respectively. In Li et al. [9], the safety factor was presented in terms of $\sigma \mathrm{ci} / \gamma \mathrm{H}$ as these three parameters can be directly measured more easily and accurately, compared with other strength parameters of the Hoek-Brown yield criterion. However, the definition in safety factor for Eq. (5) is different from that of conventional factor of safety used in limit equilibrium analysis, as shown in Eq. (6).

$\mathrm{Fs}=\Sigma$ (resisting actions) $/ \Sigma$ (driving actions)

Although both safety factors $F$ and $F$ s represent a failure when they equal 1 , due to their different definition they generally are not equal (i.e. $F \neq F s$ ). 


\subsection{Reliability}

Reliability definition is the "Probability that a system will perform its intended function for a specific period of time under a given set of conditions"

$\mathrm{R}=1-\mathrm{Pf}$

Another definition of the Reliability is the probability that unsatisfactory performance or failure will not occur [11].

\subsection{Cost of quality}

It becomes clear that the construction industry's solutions to measuring the COQ for each subcategory will vary greatly. A solution example may be as simplistic as time cards filled out by management personnel identifying the time spent on quality prevention and appraisal issues. These could provide the information needed to accurately measure the cost of many of the COQ conformance categories included under planning, training, control, measuring and evaluation costs. Another solution might be to add a couple of cost categories to existing time cards filled out by field personnel. This would assist in collecting cost data for many COQ nonconformance categories such as testing, inspections, rework, expediting, additional materials and warranty costs. There have even been attempts made by researchers to quantify the COQ for items which seem too nebulous to measure. The COQ from the loss of repeat business or poor company image leading to customer dissatisfaction is a kind of "hidden cost." Over the past several years, studies have been conducted using "probabilistic theory", "Taguchi's quality loss function", and "fuzzy logic" to quantify these types of hidden costs with varying degrees of success [12].

\subsection{Mokattam}

In this paper these methods will be adopted for the problem of rock side slopes in Gebel Mokattam which is located to the east of Cairo and is bounded by the Gebel Ahmer on the north and the Maadi-Qattamia road on the south. It is bounded on the west by the Salah Salem-Maadi and the Heliopolis-Helwan highway. Gebel Mokattam has two plateaus which are structurally controlled by major faults. The lower one has a steep scarp overlooking the eastern side of Cairo. This plateau is 140 meters above sea level and is named the middle plateau of Gebel Mokattam. This plateau is made up mainly of white, resistant limestone beds of middle Eocene age [13].

Several researches dealt with slope stability from different points of view such as the relationship between reliability index, factor of safety and probability of failure with the length of support. These studies did not take into consideration connection between these relationships and cost. But the current study aims to suggest novel technique for relating the optimal length of support that meets the optimal reliability index and cost [14].

It is well known that the common approach, which models soil properties as random variables, can lead to an overestimation of the probability of the failure of a slope because this assumption usually leads to the overestimation of the level of uncertainty [15].

As an alternative approach to the widely used limit equilibrium method, the finite element Method is increasingly being employed in reliability-based Slope stability analyses. FEMbased approaches can compute the failure probability for the critical slip surface or the system probability of slope failure [16].

\section{Methodology}

In order to find out whether the stability of rock side slope in Mokattam area is reliable or not; A model was created using Slide program for middle plateau. The model consisted of 1 layer of rock and was extended $50 \mathrm{~m}$ in X direction, $15 \mathrm{~m}$ upward from the right side and $7.5 \mathrm{~m}$ upward from the left side in $\mathrm{Y}$ direction with a perpendicular slope angle $90^{\circ}$ as shown in (figure 1 ). 


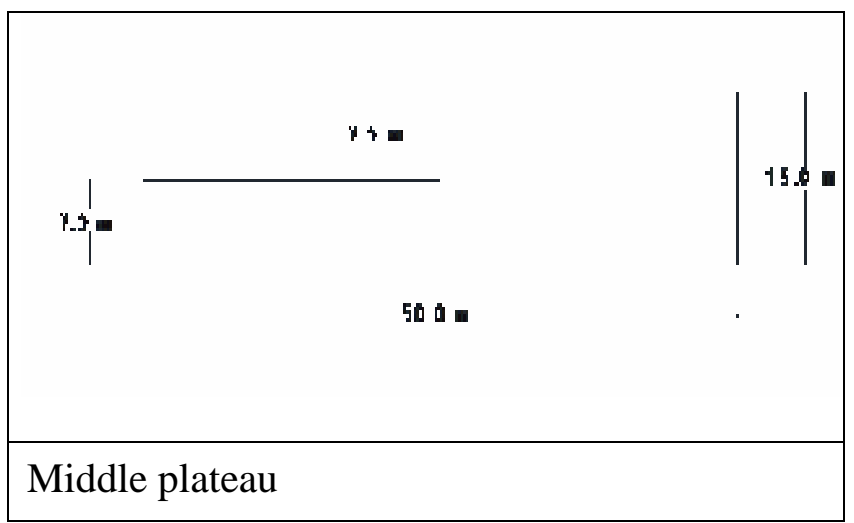

Figure 1 shows the model for middle plateau

In the beginning, the values of the rock parameters were collected and arranged. These rock parameters values were actually taken from a previous work carried out by [13]. Subsequently, statistical analysis (Maximum, Mean, Minimum and Standard deviation) of the collected data was calculated for middle plateaus, as which shown in Table 1. Finally, these values were inserted as an input data into RocData program, to get the Hoek Brown parameters (m.s).

Table 1 rock parameters for middle plateau [13].

\begin{tabular}{|c|c|c|c|}
\hline Test number & U.C.S & Unit weight & $\mathbf{E i}$ \\
\hline 1 & 28.8 & 23 & 4344 \\
\hline 2 & 62.4 & 23 & 8739 \\
\hline 3 & 35 & 21 & 5999 \\
\hline 4 & 27 & 23 & 2550 \\
\hline 5 & 42 & 21 & 4311 \\
\hline 6 & 27 & 22 & 4590 \\
\hline 7 & 36 & 23 & 5974 \\
\hline 8 & 50 & 22 & 6039 \\
\hline 9 & 26 & 23 & 5146 \\
\hline 10 & 47.8 & 21 & 6923 \\
\hline 11 & 63.2 & 23 & 9633 \\
\hline 12 & 32 & 23 & 8571 \\
\hline 13 & 23.4 & 22.5 & 2375 \\
\hline 14 & 46.3 & 22 & 6428 \\
\hline 15 & 63.2 & 23 & 9633 \\
\hline 16 & 64 & 23 & 8529 \\
\hline 17 & 37 & 24 & 3083 \\
\hline 18 & 63.2 & 21.5 & 6628 \\
\hline 19 & 64 & 21 & 5610 \\
\hline
\end{tabular}


RELIABILITY BASED DESIGN OF THE ROCK SIDE SLOPE FOR MIDDLE PLATEAU IN MOKATTAM AREA CONSIDERING OPTIMAL COST VALUE

\begin{tabular}{|l|l|l|l|}
\hline 20 & 38.4 & 22 & 5833 \\
\hline 21 & 46.3 & 22 & 7257 \\
\hline 22 & 32.6 & 23 & 5021 \\
\hline 23 & 78.9 & 22 & 7253 \\
\hline 24 & 26.4 & 23 & 2368 \\
\hline 25 & 36 & 23 & 3000 \\
\hline 26 & 54.7 & 21 & 5250 \\
\hline
\end{tabular}

Statistical analysis of testing rock parameters for middle plateaus

To determine the form of the statistical distribution for the values of the rock parameters, whose data was collected, "Bell Shape" diagrams for the values of the rock parameters for middle plateaus had been estimated as shown in figures $2,3 \& 4$.

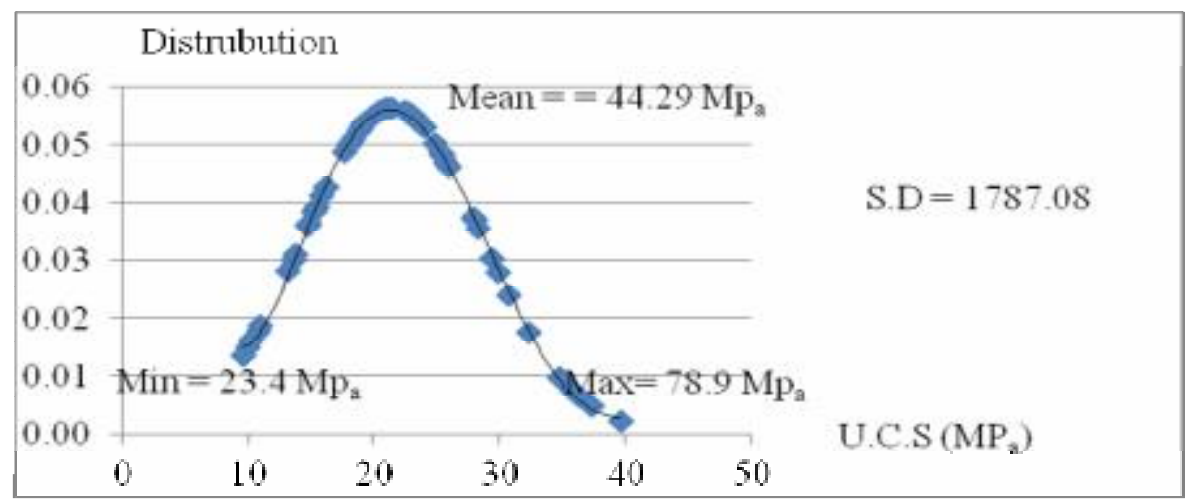

Figure 2 Bell shape for U.C.S of middle plateau

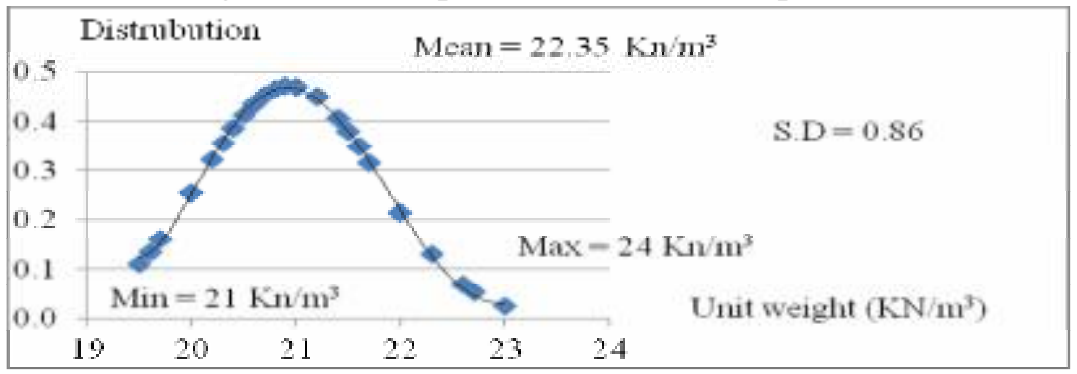

Figure 3 Bell shape for unit weight of middle plateau

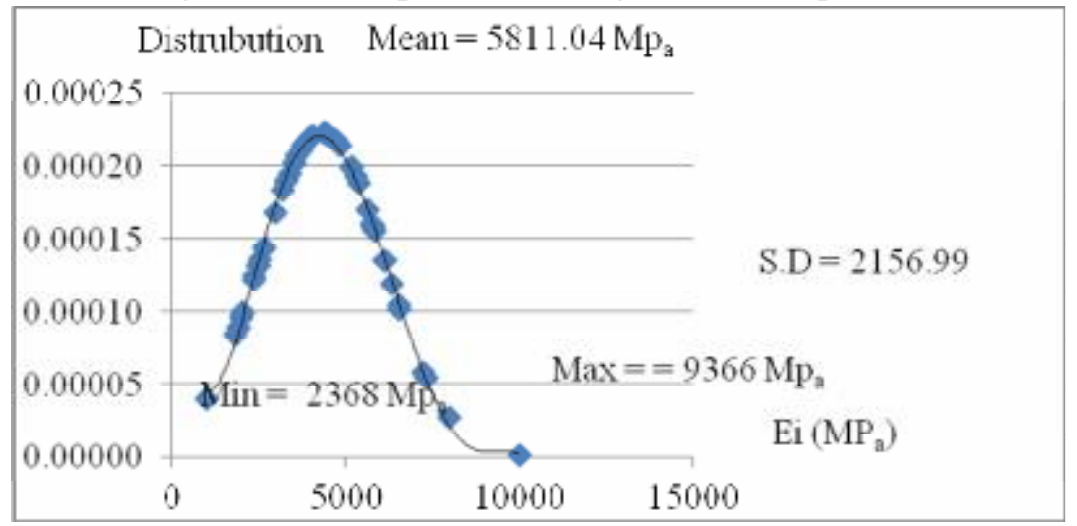

Figure 4 Bell shape for Ei of middle plateau

\subsection{Reliability and factor of safety Calculation}


To estimate Hoek Brown parameters ( $\mathrm{m}, \mathrm{s}$ ), the maximum value of each parameter had to be inserted separately with the average values of the remaining parameters in the RocData program. The previous step was then repeated, taking into consideration the insertion of the mean value of each parameter separately with the average values of the remaining parameters. Reiteration of the previous step had been done through inserting the minimum value for each parameter separately, with the average values of the remaining parameters. Afterwards, the Hoek-Brown parameters ( $\mathrm{m}, \mathrm{s})$, for each case, were obtained from RocData program. Later the Hoek- Brown parameters (m, s), unit weight and uniaxial compressive strength (U.C.S) values got entered into slide program. Noting that the determination of the suitable statistical distribution of the previous parameters were thoroughly considered by using LAB Fit program. Table 2 shows reliability index and factor of safety Values for middle plateau, Table 3 shows the best distribution using LAB Fit program for middle plateau. From the previous steps, the reliability Index, factor of safety, and probability of failure were gotten. If the reliability Index is greater than or equal 3, there is no need for the reinforcement (rock nailing). Otherwise, we must improve the reliability by using rock bolts. Noting that reliability index of at least 3 is usually recommended as a minimal assurance of a safe slope design.

Table 2 Values of R.I and F.S for middle plateau

\begin{tabular}{|l|l|l|l|}
\hline \multicolumn{4}{|l|}{ Middle plateau } \\
\hline \multirow{2}{*}{ Parameters } & $\begin{array}{l}\text { Material } \\
\text { Properties }\end{array}$ & R.I & F.S \\
\hline \multirow{3}{*}{ U.C.S } & Max & 4.262 & 2.111 \\
\cline { 2 - 4 } & Mean & 1.946 & 1.416 \\
\cline { 2 - 4 } & Min & 0.003 & 1.001 \\
\hline \multirow{3}{*}{ G.S.I } & Max & 3.277 & 2.233 \\
\cline { 2 - 4 } & Mean & 1.946 & 1.416 \\
\cline { 2 - 4 } & Min & 0.374 & 1.054 \\
\hline \multirow{3}{*}{ Mi weight } & Max & 1.815 & 1.37 \\
\cline { 2 - 4 } & Mean & 1.946 & 1.416 \\
\cline { 2 - 4 } & Min & 2.067 & 1.462 \\
\hline \multirow{3}{*}{ Ei } & Max & 2.237 & 1.431 \\
\cline { 2 - 4 } & Mean & 1.946 & 1.416 \\
\cline { 2 - 4 } & Min & 1.666 & 1.421 \\
\hline \multirow{3}{*}{ D } & Max & 1.946 & 1.416 \\
\cline { 2 - 4 } & Mean & 1.946 & 1.416 \\
\cline { 2 - 4 } & Min & 1.946 & 1.416 \\
\hline \multirow{3}{*}{ Slope Height } & Max & 1.475 & 1.284 \\
\cline { 2 - 4 } & Mean & 1.946 & 1.416 \\
\cline { 2 - 4 } & Min & 2.801 & 1.728 \\
\cline { 2 - 4 } & Min & 2.761 & 1.576 \\
\hline \multirow{3}{*}{} & & 3.946 & 1.416 \\
\hline
\end{tabular}

Table 3 the best distribution for middle plateau using LAB Fit program

The best distribution for middle plateau using LAB Fit program

\begin{tabular}{|l|l|l|l|l|}
\hline Parameters & Hoek-Brown m parameter & UCS & Unit Weight & Hoek-Brown s parameter \\
\hline Distribution & Normal & Gamma & Normal & Lognormal \\
\hline
\end{tabular}

2.2.Length of rock bolt and tensile strength calculating: 
To indicate the calculation of the length for rock bolt and tensile strength, the researcher considered the following:

Equivalent cohesion and internal friction $(c \& \varphi)$ from RocData program was obtained

The calculation of the length for rock bolt and tensile strength, using design of rock nail walls of Federal Highway Administration (FHWA), had been applied [17]. New probability parameter such as (inclination angle, support length, distance between supports, out of plan spacing, tensile capacity, plate capacity and bond strength) had been added as input data in Slide program as shown in Table 4 for middle plateau.

The maximum value of each parameter got inserted separately with the average values of the remaining parameters in the Slide program. The previous step was then repeated, taking into consideration the insertion of the mean value of each parameter separately with the average values of the remaining parameters. Reiteration of the previous step had been done through inserting the minimum value for each parameter separately, with the average values of the remaining parameters to obtain the R.I, F.S and Pf.

Table 4 Probability for the rock nails for middle plateau

\begin{tabular}{|c|c|c|c|c|c|c|c|}
\hline \multicolumn{8}{|c|}{ middle plateau with support } \\
\hline Parameters & $\begin{array}{c}\text { Inclination } \\
\text { Angle }\left(^{\circ}\right)\end{array}$ & $\begin{array}{l}\text { Support } \\
\text { Length } \\
\text { (m) }\end{array}$ & $\begin{array}{l}\text { Distance } \\
\text { Between } \\
\text { Supports } \\
\text { (SV) (m) }\end{array}$ & $\begin{array}{l}\text { Out Of } \\
\text { Plan } \\
\text { Spacing } \\
\text { (SH) (m) }\end{array}$ & $\begin{array}{c}\text { Tensile } \\
\text { Capacity } \\
\text { (KN) }\end{array}$ & $\begin{array}{c}\text { Plate } \\
\text { Capacity } \\
(\mathrm{KN})\end{array}$ & $\begin{array}{c}\text { Bond } \\
\text { Strength } \\
(\mathrm{KN} / \mathrm{m})\end{array}$ \\
\hline Max & 20.00 & 8.95 & 2.00 & 2.12 & 48.79 & 751.00 & 400.00 \\
\hline Mean & 15.00 & 8.13 & 1.50 & 1.41 & 40.65 & 339.50 & 350.00 \\
\hline St.dev & 3.32 & 0.27 & 0.40 & 0.47 & 4.79 & 185.79 & 39.53 \\
\hline Min & 10.00 & 5.93 & 1.00 & 0.71 & 31.02 & 118.00 & 300.00 \\
\hline
\end{tabular}

3. Result

3.1. Results of the unsupported rock side slope for middle plateau

The relationship between the reliability index (R.I) and parameters of rock had been plotted and the next figures (5 and 6) show these relationships. It was clear that the larger the increase in the uni-axial compressive strength (U.C.S), the larger was the increase in reliability index (R.I). Similarly geological strength index (G.S.I) and factor depended on rock type and texture (mi). Furthermore it was clear that the larger the increase in unit weight, the lower was the decrease in reliability index (R.I). Similarly disturbance factor (D) and Slope Height. Moreover, it was obvious that the reliability index was constant and did not change due to the changing in young's modulus (Ei) which meant that this parameter had absolutely no effect (deformation parameter).

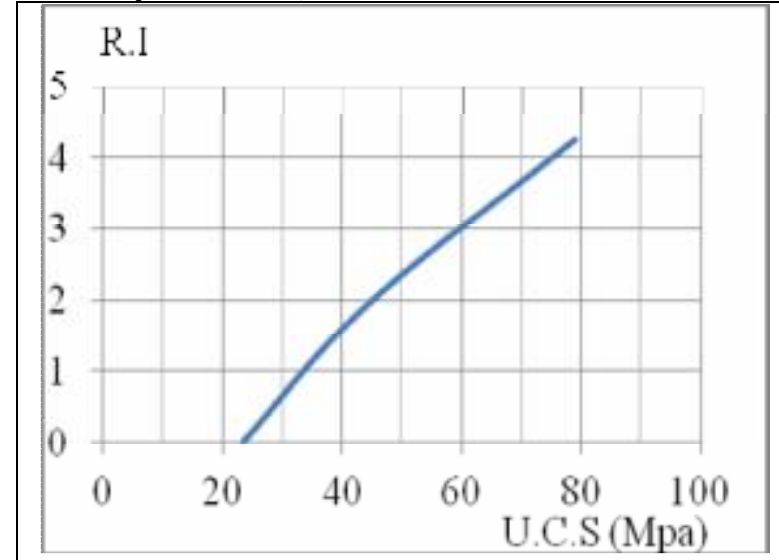

Figure 5 Relationships between R.I and U.C.S for middle plateau

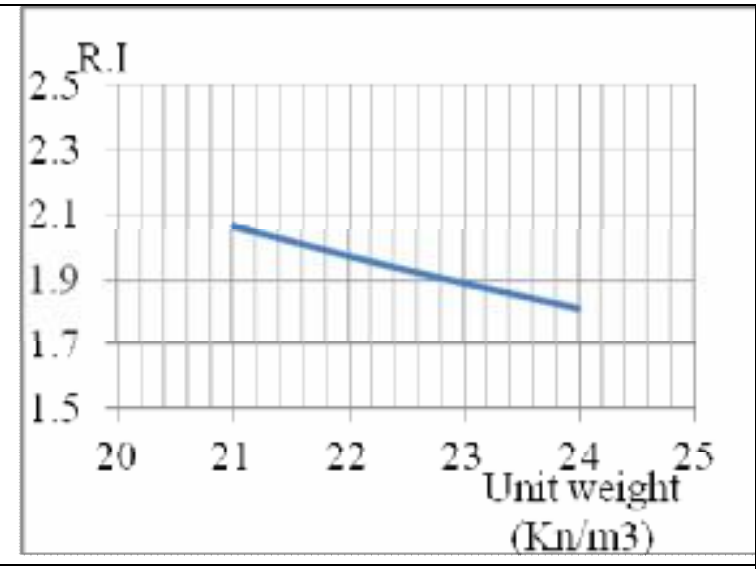

Figure 6 Relationships between R.I and unit weight for middle plateau

3.2. Results of the supported rock side slope for middle plateau 
The relationship between the reliability index (R.I) and parameters of rock had been plotted and the next figures (7 and 8) show these relationships. It was clear that the larger the increase in inclination angle, the lower was the decrease in reliability index. Similarly distance between supports and out of plan spacing. Furthermore, it was obvious that the larger the increase in tensile capacity, the larger was the increase in reliability index.

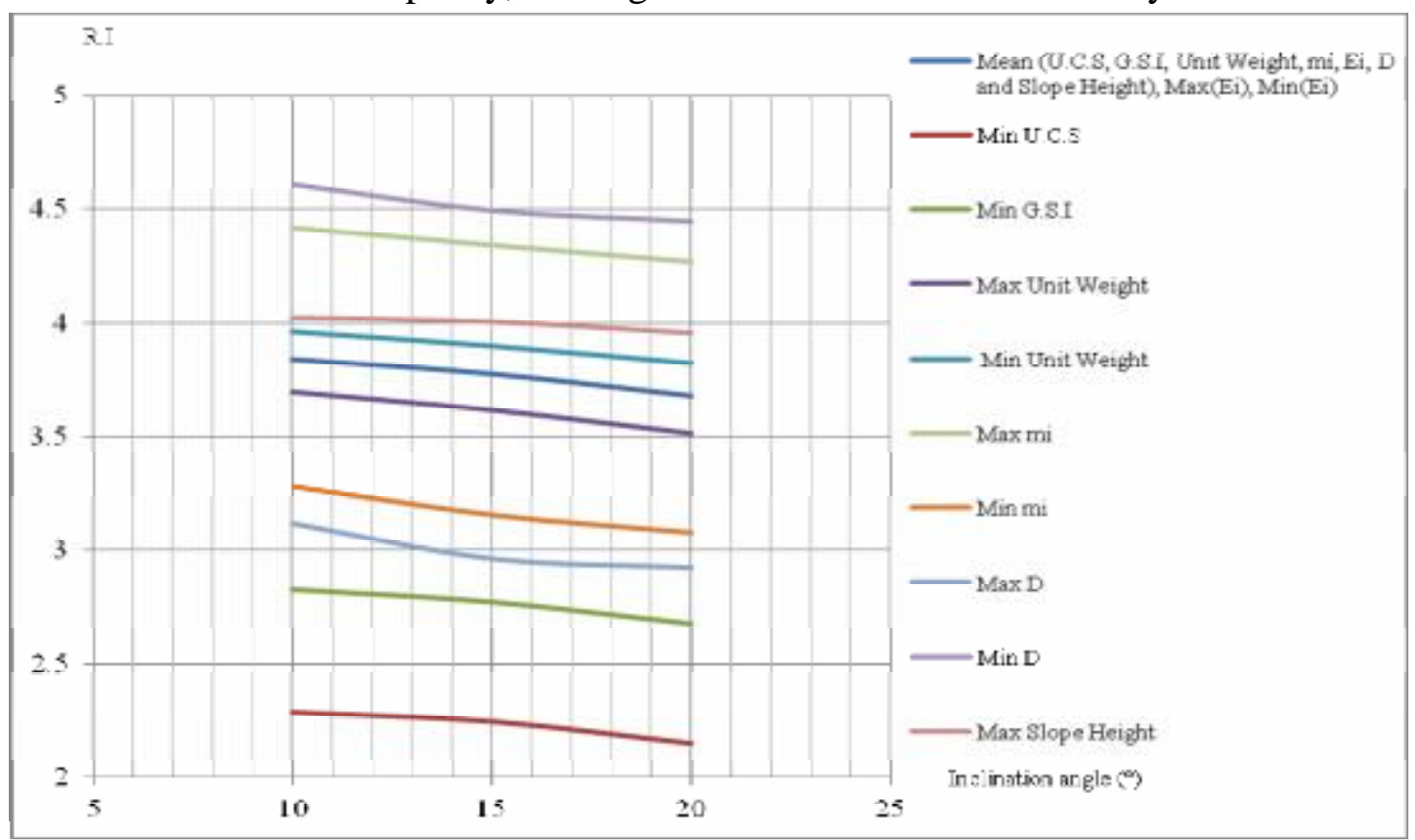

Figure 7 Relationships between R.I and inclination angle for middle plateau

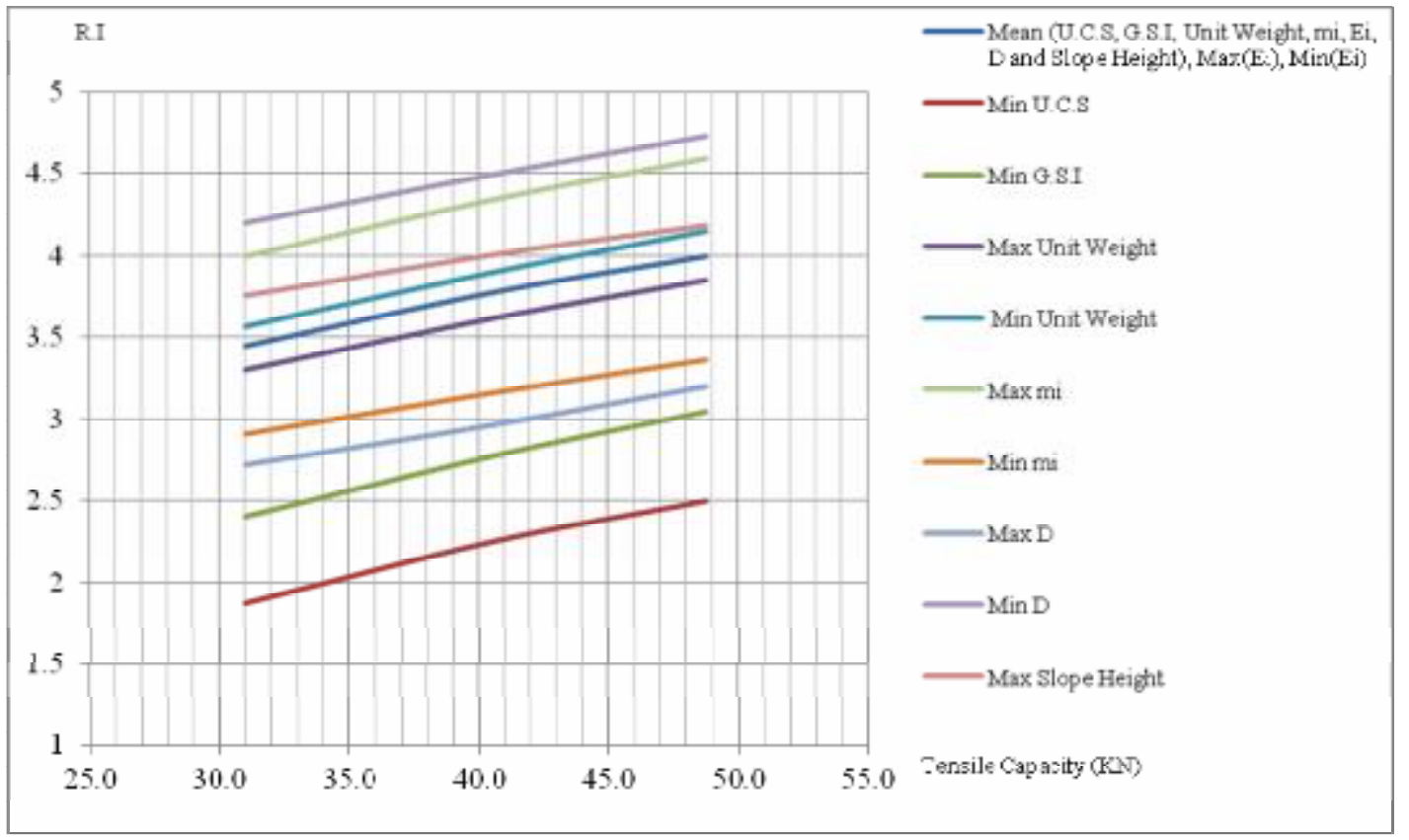

Figure 8 Relationships between R.I and tensile capacity for middle plateau

\section{Determination of the most critical parameters}


In order to calculate the most critical parameter, the following equation must be calculated for each parameter, Table 5 shows the values of the (Mean + St.dev), (Mean) and (Mean - St.dev) of the rock parameters for middle plateau.

Most critical parameter $=$ R.I of (Mean + St.dev) - R.I of (Mean-St.dev) / 3 (for any parameter)

Table 5 Probability of rock parameters for middle plateau (most critical parameter)

\begin{tabular}{|l|l|l|l|l|l|l|l|}
\hline Parameters & U.C.S (MPa) & G.S.I & unit weight(KN/m3) & mi & Ei (MPa) & D & $\begin{array}{l}\text { slope } \\
\text { height (m) }\end{array}$ \\
\hline $\begin{array}{l}\text { Mean } \\
\text { St.dev }\end{array}$ & 59.87 & 42.05 & 23.20 & 11.16 & 7968.03 & 0.98 & 9.37 \\
\hline Mean & 44.29 & 37.00 & 22.35 & 9.00 & 5811.04 & 0.85 & 7.50 \\
\hline St.dev & 15.58 & 5.05 & 0.86 & 2.16 & 2156.99 & 0.13 & 1.87 \\
\hline $\begin{array}{l}\text { Mean- } \\
\text { St.dev }\end{array}$ & 28.71 & 31.95 & 21.49 & 6.84 & 3654.04 & 0.72 & 5.63 \\
\hline
\end{tabular}

Afterwards, the values of the (Mean + St.dev) and (Mean - St.dev) for the rock parameters should be inserted into the Slide program, and Table 6 shows the values of the R.I for middle plateau.

Table 6 Values of R.I for middle plateau (most critical parameter)

\begin{tabular}{|c|c|c|}
\hline \multicolumn{3}{|c|}{ middle plateau (most critical parameter) } \\
\hline Parameters & Probability & R.I \\
\hline \multirow{2}{*}{ U.C.S } & Mean + Standard deviation & 2.946 \\
\cline { 2 - 3 } & Mean - Standard deviation & 1.946 \\
\hline \multirow{2}{*}{ G.S.I } & Mean + Standard deviation & 0.835 \\
\cline { 2 - 3 } & Mean - Standard deviation & 3.792 \\
\hline \multirow{2}{*}{ unit weight } & Mean + Standard deviation & 1.946 \\
\cline { 2 - 3 } & Mean - Standard deviation & 1.896 \\
\hline \multirow{2}{*}{ mi } & Mean + Standard deviation & 1.884 \\
\cline { 2 - 3 } & Mean - Standard deviation & 1.946 \\
\hline \multirow{2}{*}{ Ei } & Mean + Standard deviation & 2.012 \\
\cline { 2 - 3 } & Mean - Standard deviation & 2.155 \\
\hline & Mean + Standard deviation & 1.946 \\
\cline { 2 - 3 } & Mean - Standard deviation & 1.668 \\
\hline \multirow{2}{*}{ slope } \\
height & Mean + Standard deviation & 1.946 \\
\cline { 2 - 3 } & Mean - Standard deviation & 1.946 \\
\hline
\end{tabular}

Finally, the values of the most critical parameter for upper and middle plateau had been calculated and Table 7 shows the values of the percentage of the most critical parameter for middle plateau. 
RELIABILITY BASED DESIGN OF THE ROCK SIDE SLOPE FOR MIDDLE PLATEAU IN MOKATTAM AREA CONSIDERING OPTIMAL COST VALUE

Table 7 Calculations of the most critical parameters for middle plateau

\begin{tabular}{|l|l|l|l|l|l|l|l|}
\hline Most critical parameter for middle plateau \\
\hline Parameters & $\begin{array}{l}\text { U.C.S } \\
(\mathrm{MPa})\end{array}$ & G.S.I & $\begin{array}{l}\text { unit } \\
\text { weight } \\
(\mathrm{KN} / \mathrm{m} 3)\end{array}$ & $\mathrm{mi}$ & $\begin{array}{l}\mathrm{Ei} \\
(\mathrm{MPa})\end{array}$ & D & $\begin{array}{l}\text { slope } \\
\text { height (m) }\end{array}$ \\
\hline $\begin{array}{l}\text { calculation the most } \\
\text { critical parameters }\end{array}$ & $70.37 \%$ & $63.20 \%$ & $4.27 \%$ & $16.23 \%$ & $0 \%$ & $\begin{array}{l}51.37 \\
\%\end{array}$ & $46.67 \%$ \\
\hline
\end{tabular}

\section{Determination of the total number of supports}

1. For middle plateau

There are 3 cases for calculating number of supports in $\mathrm{Z}$ direction according to the length of distance between supports:

In case of the distance between supports $=$ maximum $(2 \mathrm{~m})$, the number of supports in $\mathrm{Z}$ direction will be 4

In case of the distance between supports $=$ mean $(1.5 \mathrm{~m})$, the number of supports in $\mathrm{Z}$ direction will be 6

case of the distance between supports $=$ minimum $(1 \mathrm{~m})$, the number of supports in $\mathrm{Z}$ direction will be 8

There are 3 cases for calculating number of supports in $\mathrm{Y}$ direction / $\mathrm{m}$ ` according to the length of out of plan spacing:

In In case of the out of plan spacing = maximum $(2.12 \mathrm{~m})$, the number of supports in $\mathrm{Z}$ direction will be 1

In case of the out of plan spacing $=$ mean $(1.41 \mathrm{~m})$, the number of supports in $\mathrm{Z}$ direction will be 2

In case of the distance between supports $=$ minimum $(0.71 \mathrm{~m})$, the number of supports in $\mathrm{Z}$ direction will be 3

So the total number of supports $=$ number of supports in $\mathrm{Z}$ direction $*$ number of supports in $\mathrm{Y}$ direction / $\mathrm{m}^{`}$ (according to the case studied).

Relationship between R.I and the total number of supports

The following figure 9 shows the relationship between reliability and total length of supports considering that:

Total length of support $=$ Support Length $*$ Total number of supports

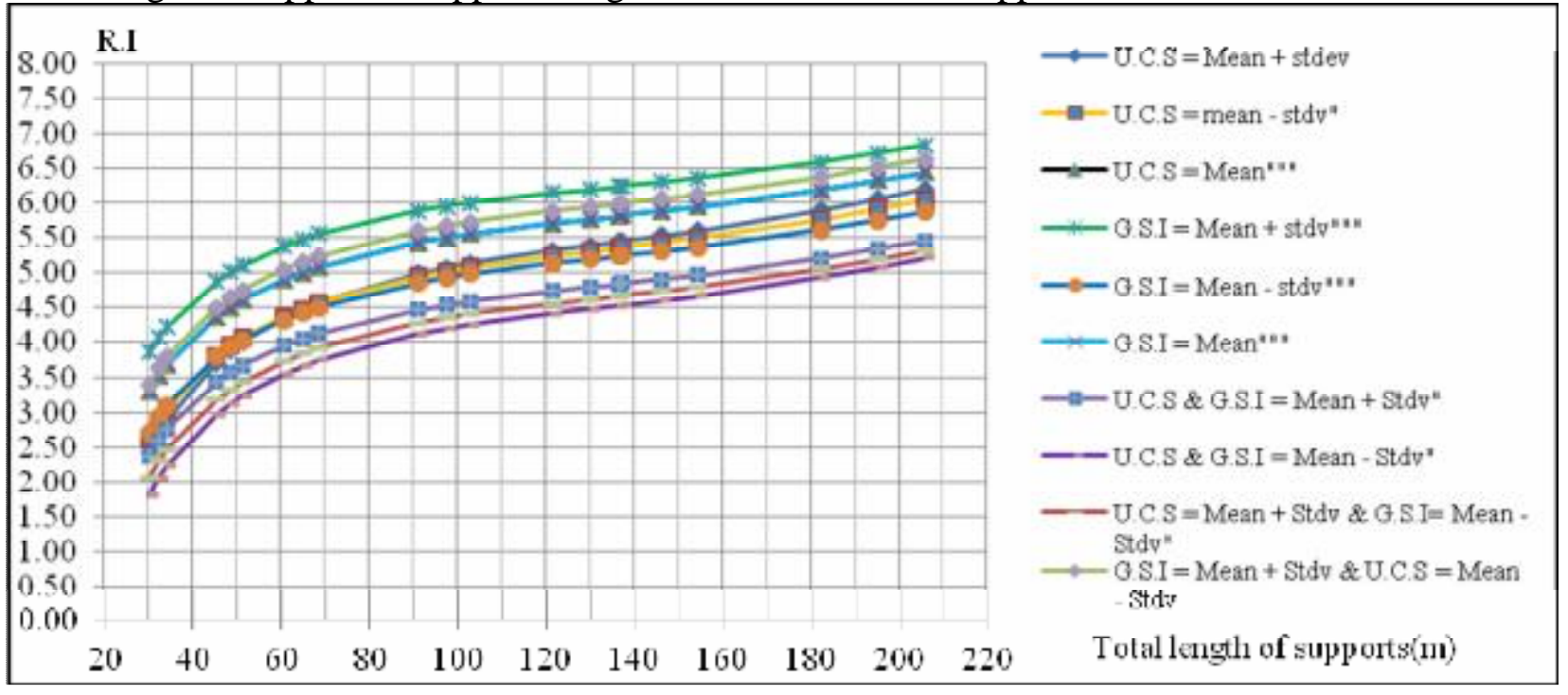

Figure 9 Relationships between R.I and total length of supports for middle plateau

\section{COST OF APPRAISAL AND COST OF FAILURE}

In order to calculate the cost of quality, cost of appraisal and cost of failure must be calculated

Cost of appraisal $=$ length of the rock bolt $* \operatorname{cost} / \mathrm{m}^{\prime}$

Cost of failure $=$ probability of failure $* \cos t / \mathrm{m}^{\prime}$ 
Figures (10, 11 and 12) show the relationship between the cost of appraisal, cost of failure, total cost and the total length of support for middle plateau for different cases of the most 2 critical rock parameters

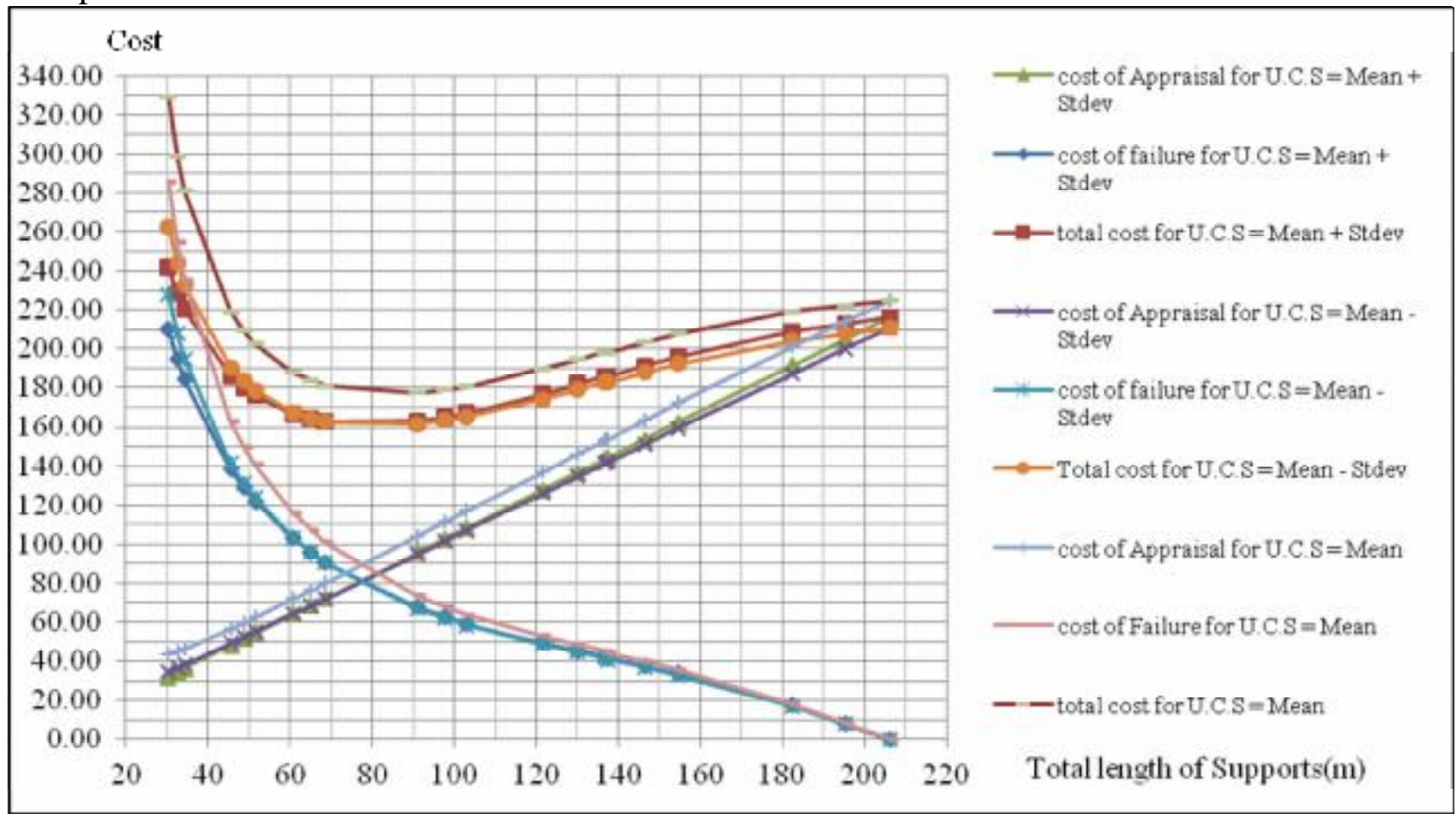

Figure 10 shows the relationship between the cost of Appraisal, cost of failure, total cost and the total length of support for middle plateau for different values of U.C.S

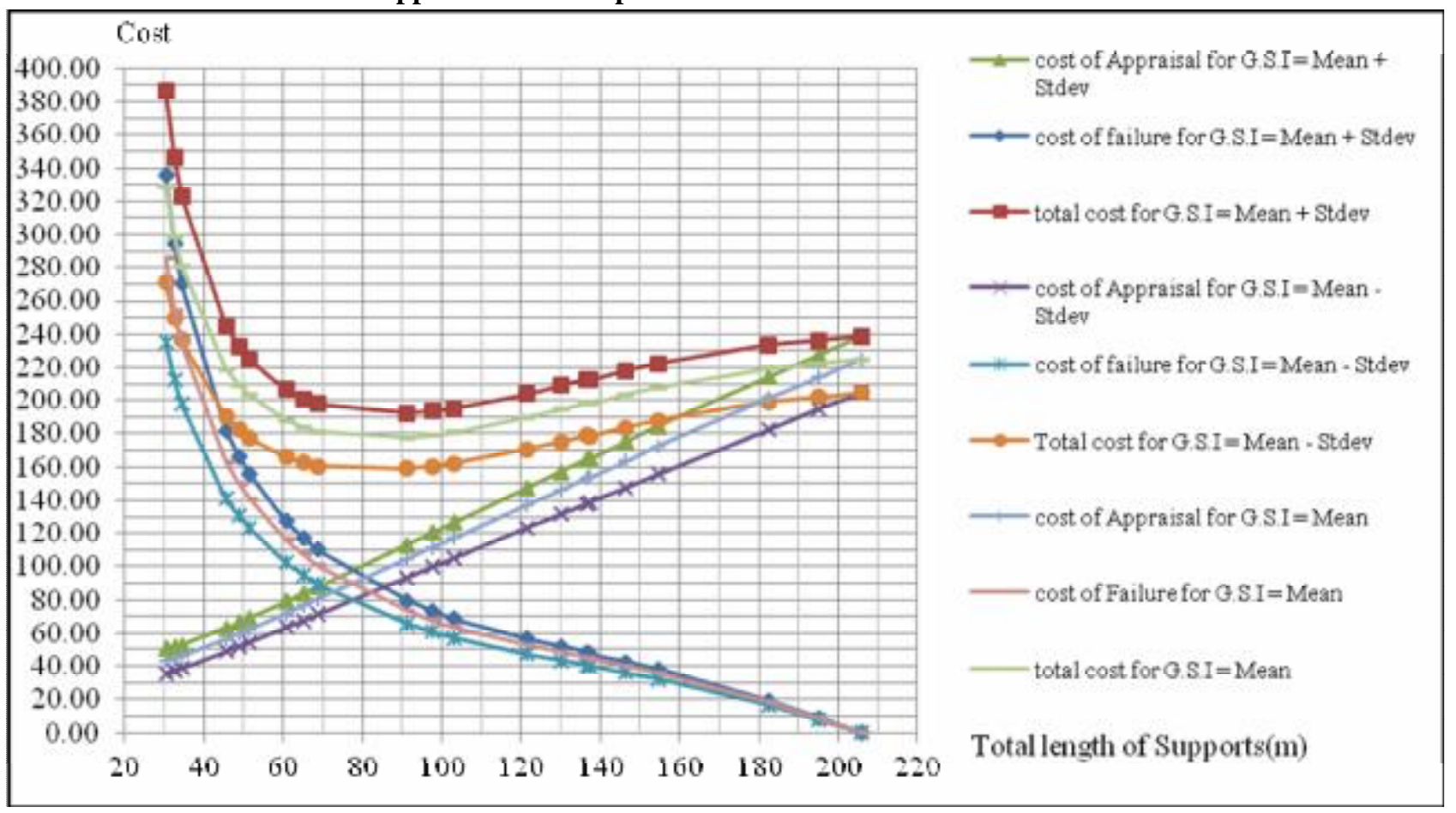

Figure 11 shows the relationship between the cost of Appraisal, cost of failure, total cost and the total length of support for middle plateau for different values of G.S.I 


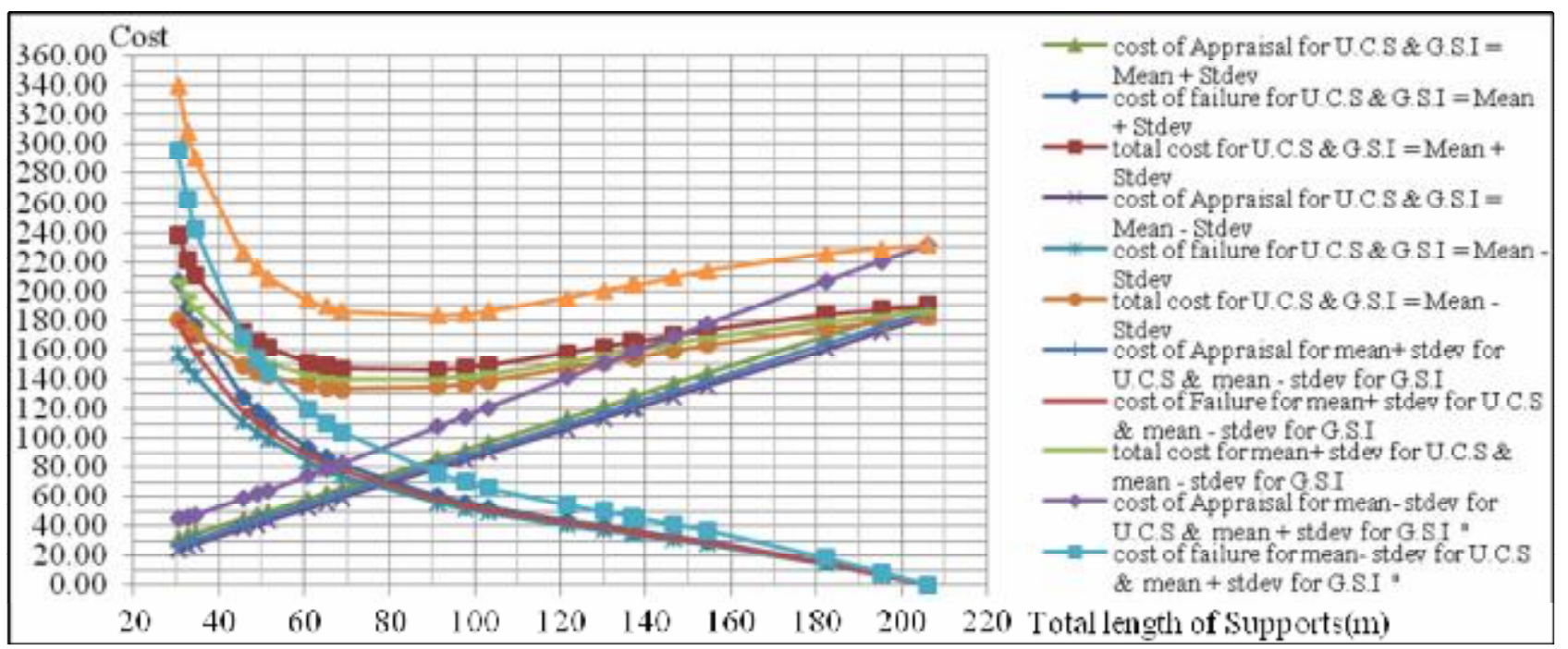

Figure 12 shows the relationship between the cost of Appraisal, cost of failure, total cost and the total length of support for middle plateau for different values of U.C.S \& G.S.I

\section{CONCLUSIONS}

Methodology used in this thesis is suitable for the rock side slope. Hoek Brown Criterion had been used, which, with the help of statistical methods, gives results that are more accurate. Moreover, reliability index, support length and cost were calculated to help in reaching the optimal value for the three parameters. In the case of middle plateau: all values for all parameters for minimum (U.C.S) did not achieve minimum "Reliability Index", except the values of the minimum distance between supports and out of plan spacing. All values for all parameters for minimum (G.S.I) did not achieve the minimum "Reliability Index", except the values of the minimum distance between supports, out of plan spacing, and the value of the maximum tensile capacity. When the value of out of plan spacing was maximum, for minimum (mi), the reliability index was less than the minimum reliability index, and that meant that it failed. When the value of tensile capacity was minimum, for minimum (mi), the "Reliability Index" was less than the minimum "Reliability Index", and that meant that it failed. All values for all parameters for maximum "D" did not achieve the minimum "Reliability Index", except the values of the minimum inclination angle, distance between supports, out of plan spacing, and the value of the maximum tensile capacity. It is, therefore, concluded that for middle plateau, the larger the increase in "Inclination Angle", the larger is the increase in the "Reliability Index". For middle plateau, it is obvious that the "Reliability Index" is constant and not changing, due to the changing of support length, which means that this parameter has absolutely no effect, (deformation parameter).

The research, therefore, concludes the following:

1. The larger the increase in distance between supports, the lower is the decrease in "Reliability Index" for all the parameters. The larger the increase in out of plan spacing, the lower is the decrease in "Reliability Index" for all the parameters.

2. For middle plateaus, the larger the increase in tensile capacity, the larger is the increase in "Reliability Index" for all the parameters.

3. "Reliability Index" has been proven to remain constant and does not change due to the change of plate capacity. This means that this parameter has absolutely no effects.

4. "Reliability Index" also remains constant and does not change due to the change of bond strength. This means that this parameter has absolutely no effects (deformation parameter) 


\section{REFERENCES}

Hoek, E. (1994). “Strength of Rock \& Rock Masses.” ISRM, New Journal, 2(2), 4-16

Yan Kou. (2015). "Wedge failure analysis of anchored rock slopes subjected to surcharge and seismic loads." Edith Cowan University Research, Master's Thesis.

Hearn, G. J. (2011). Geological Society, London, Engineering Geology Special Publications, 24, 189-208.

Peter G. F. and Michael S. (1976). Slopes Stabilization and control of local rock falls and degrading rock, Quarterly Journal of Engineering Geology and Hydrogeology, v.9, p37-55.

Miranda, L. (2011). "The geotechnical variability influence on the subsidence caused by urban tunnel excavation". M.Sc Thesis in Civil Engineering. Instituto Superior Técnico, Lisboa. (In Portuguese).

Merifield RS, Lyamin AV, Sloan SW. (2006). Limit analysis solutions for the bearing capacity of rock masses using the generalised Hoek-Brown criterion. Int J Rock Mech Min Sci; 43:920-37.

Li AJ, Merifield RS, Lyamin AV. (2008) Stability charts for rock slopes based on the HoekBrown failure criterion. Int J Rock Mech Min Sci; 45(5):689-700.

Li AJ, Lyamin AV, Merifield RS. Seismic rock slope stability charts based on limit analysis methods. Comput Geotech (2009), 36(1-2):135-48.

Li AJ, Merifield RS, Lyamin AV. (2011) Effect of rock mass disturbance on the stability of rock slopes using the Hoek-Brown failure criterion. Compute Geo-tech; 38(4):546-58.

Hoek E, Carranza-Torres C, Corkum B. Hoek-Brown (2002). failure criterion edition. In: Proceedings of the North American rock mechanics society meeting in Toronto; 2002.

Robert C. Patev, (2002) Introduction to Engineering Reliability.

Selles, M. E. S., Rubio, J. A. C., \& Mullor, J. R. (2008). Development of a quantification proposal for hidden quality costs: Applied to the construction sector. Journal of Construction Engineering and Management, 134(10), 749-757.

Mohamed S. A. (1985). "Engineering geology of some areas in the greater Cairo" PH.D. Thesis submitted to faculty of engineering Ain Shams University.

Ausilio, E., Conte, E., and Dente, G. (2001). Stability analysis of slopes reinforced with piles, Computers and Geo-technics, 28, 591-611.

J. Zhang, W.H. Tang, L.M. Zhang, (2010) Efficient probabilistic back-analysis of slope stability model parameters Journal of Geotechnical and Geo-environmental Engineering, 136, p. 1 ASCE

J. Huang, D.V. Griffiths, G.A. ., (2010) Fenton System reliability of slopes by RFEM Soils and Foundations, 50 (3) (2010), pp. 343-353

Sheahan, T.C., T. Oral, and C.L. Ho (2002). "A Simplified Trial Wedge Method for Soil Nailed Wall Analysis," Journal of Geotechnical and Geo-environmental Engineering, American Society of Civil Engineers, Vol. 128, No. : TBD. 